\title{
Association between Hs-CRP and other Cardiovascular Risk Factors with Blood Pressure in Young Adults
}

\author{
Asmak A.S. ${ }^{a}$, Aszrin A. ${ }^{a}$, Nor Zamzila A. ${ }^{b}$, Aida N.S M. S. ${ }^{c}$, Azarisman S.M.S. ${ }^{d}$ \\ ${ }^{a}$ Department of Basic Medical Sciences, Kulliyyah of Medicine, International Islamic University Malaysia, Pahang, Malaysia \\ ${ }^{b}$ Department of Pathology and Laboratory Medicine, Kulliyyah of Medicine, International Islamic University Malaysia, Pahang, Malaysia \\ ${ }^{c}$ Department of Emergency Medicine, Kulliyyah of Medicine, International Islamic University Malaysia, Pahang, Malaysia \\ ${ }^{d}$ Department of Internal Medicine, Kulliyyah of Medicine, International Islamic University Malaysia, Pahang, Malaysia.
}

\section{ABSTRACT}

INTRODUCTION: Hypertension remains the leading preventable risk factor for premature mortality and morbidity worldwide. The use of high-sensitivity C-reactive protein (hs-CRP) as the global risk prediction assessment for cardiovascular diseases (CVD) in asymptomatic individuals suggests the possibility that higher hs-CRP, or subclinical inflammation, maybe one of the causal factors contributing to an increased risk of CVD in young hypertensive patients. Most studies of hypertension and hs-CRP association were conducted regionally, whereby most of the participants were Caucasians with age beyond 40 years old. Studies of this association among young adults in Asian populations are lacking, therefore, a generalization of data might be limited to certain ages and populations only. MATERIALS AND METHOD: This comparative cross-sectional study analysed the association between hs-CRP and other cardiovascular risk factors with three different blood pressure statuses categorised into Normotensive (NT), Pre-hypertensive (PHT), and Hypertensive (HPT) groups among young adults in Kuantan, Pahang, Malaysia. RESULTS: Independently, the association was significant only in males and subjects with parental history of hypertension in the prehypertensive group. However, in the hypertensive group, the relationships were significant not only in males and individuals with parental histories of hypertension but also in obese subjects. HsCRP was not associated with blood pressure status in the present study. CONCLUSION: The hypothesis that hsCRP has an independent association with blood pressure status was not demonstrated in the present study. However, the observed association between circulating hs-CRP and blood pressure status is likely to be driven by confounders namely age, gender, genetic factors, and BMI status.

KEYWORDS: High sensitivity C-Reactive Protein; Hypertension; Cardiovascular Risk Factors, Young adult

\section{INTRODUCTION}

Hypertension remains the leading preventable risk factor for premature mortality and morbidity worldwide ${ }^{1}$. It shows a substantial variation between ethnic groups with

\section{Corresponding Author:}

Asst. Prof. Dr. Aszrin Abdullah

Department of Basic Medical Sciences,

Kulliyyah of Medicine,

International Islamic University Malaysia, Jalan Sulan Ahmad Shah, Bandar Indera Mahkota, 23200 Kuantan, Pahang, Malaysia

Tel No: +60139230011

E-mail: draszrin@iium.edu.my the highest rates among African-American women. Data from the National Health and Nutrition Examination Survey (NHANES) for 2011 to 2014 showed that the prevalence of hypertension was highest among nonHispanic black adults $(41.2 \%)$ compared to other ethnicities namely non-Hispanic whites (28.0\%), Asian $(24.9 \%)$, and Hispanic $(25.9 \%)$ adults ${ }^{2}$. Hypertension is usually preceded by prehypertension, and without intervention, prehypertension may lead to hypertension at an accelerated rate 3,4 . 
The prominent Framingham Heart Study led to the identification of multiple risk factors of cardiovascular diseases (CVD). Age, sex, ethnicity, genetic factors, elevated blood pressure, hyperglycaemia, hyperlipidaemia or dyslipidaemia, and being overweight or obese are some of the more established cardiovascular risk factors. ${ }^{5-7}$ Newer risk factors such as biochemical and subclinical disease markers for instance lipoprotein (a), C-Reactive Protein, homocysteine, and markers of fibrinolytic and hemostatic function such as fibrinogen, D-dimer, tissue plasminogen activator, and plasminogen activator inhibitor-1 antigen, are also identified as risk factors for these diseases 8,9 . Based on many reports ${ }^{10-14}$, CRP is regarded as an independent risk factor in the development of CVD through its active participation in atherosclerosis. This involves its influence to activate the complement system, apoptosis, vascular cell activation, monocyte recruitment, lipid accumulation, and thrombosis by both isoforms, mCRP and pCRP.15

Numerous large studies have been conducted to view the association between hypertension and CRP. The study by Sesso et al. (2003) concluded that hs-CRP levels are associated with future development of hypertension suggesting involvement of inflammation in the process. However, most studies were conducted among western populations in which, most of the participants are Caucasians aged beyond 40 years old. The relationship is not reported in younger Asian people, so the generalization of existing data can only be limited to specific ages and demographics. This study aimed to assess the association between hs-CRP and other cardiovascular risk factors with blood pressure status, among young adults in Kuantan, Pahang Malaysia.

\section{MATERIALS AND METHODS}

This comparative cross-sectional study analyses the association between hs-CRP and other cardiovascular risk factors with three different blood pressure statuses categorized into Normotensive (NT), Pre-hypertensive (PHT), and Hypertensive (HPT) groups. The categorization is in accordance with The Seventh Report of the Joint National Committee on Prevention, Detection, Evaluation, and Treatment of High Blood
Pressure (JNC 7) produced in 2003. The Normotensive (NT) group is categorised as systolic blood pressure (SBP) of below $120 \mathrm{~mm} \mathrm{Hg}$ and diastolic blood pressure (DBP) less than $80 \mathrm{~mm} \mathrm{Hg}$. Subjects with SBP between 120 to $140 \mathrm{~mm} \mathrm{Hg}$ and/ or DBP with a range of 80 to $90 \mathrm{~mm} \mathrm{Hg}$ are classified as Pre-hypertensive (PHT) group. Whilst subjects with SBP and/ or DBP of (or more than) 140- and 90-mm $\mathrm{Hg}$ respectively, are classified into mild hypertensive (HPT) group. Ethics approval was obtained from the Institutional (International Islamic University Malaysia, IIUM) Research Ethics Committee (IREC ID No: 544) and the Malaysian Medical Research Ethics Committee (MREC, NMRR 16-2572-32869) which operates following the Declaration of Helsinki. Written informed consent was obtained from each patient.

\section{Subject recruitment and the study protocol}

A total of 315 young adults (age range between 18 and 45 years old) from Kuantan, Pahang were involved in the study. Recruitment was carried out from January 2016 to November 2017. 43 subjects were excluded due to multiple reasons leaving a total of 272 subjects for analysis. The main inclusion criterion was subjects aged 18 to 45 , which is considered young adults ${ }^{11,12}$. Subjects other than those defined as a young adult; or with endorgan damage or hypertensive complications; alcoholic; pregnant and lactating females or those on regular oral contraceptive were excluded from this study. Diabetics, as well as subjects with the previous diagnosis of hypertension or, has been on anti-hypertensive medications were also excluded. All subjects were ensured to be free of any type of infection, inflammation, or traumatic injury at least two weeks prior to appointment and followed a pre-test, ten-hour fasting protocol prior to sample collection.

Full history with particular emphasis on own medical and family history as well as other social-demographic data were elicited, together with anthropometry measurements such as weight, height, and waist circumference and followed by blood pressure and pulse rate measurements. Blood pressure was measured using a recently validated automated digital blood pressure monitor (Omron HEM-7130). Three different blood pressure measurements were taken at different 
occasions (screening, time of sample collection, and consultation day) to confirm genuine cases. The average blood pressure on each occasion was used to categorize the subjects. On average, the interval between the screening, time of sample collection, and consultation day during result presentation was seven days.

\section{Biochemical analyses}

All biochemical profiles were outsourced to an accredited pathology laboratory and analysed using Advia 2400 Chemistry Analyser, following the welldocumented Advia 2400 User Manual for the biochemical parameters involved.

\section{Statistical analysis}

Data were analysed using SPSS statistical software Version 23.0. Multinomial Logistic Regression Analysis was conducted to describe the association of the cardiovascular risk factors with blood pressure status both in unadjusted and adjusted models.

\section{RESULTS}

From 272 subjects, males outnumbered females by more than $20 \%$. The majority of the participants were Malays

Table 1 Overall baseline characteristics of the study subjects

\begin{tabular}{|c|c|c|}
\hline Variables & $N,(n=272)$ & Mean (SD) or $\%$ \\
\hline Age, year & & $33.5(7.1)$ \\
\hline \multirow[t]{2}{*}{ Gender } & Male & 65.4 \\
\hline & Female & 34.6 \\
\hline \multirow[t]{4}{*}{ Race } & Malay & 91.9 \\
\hline & Chinese & 6.6 \\
\hline & Indian & 0.7 \\
\hline & Others & 0.7 \\
\hline \multirow[t]{3}{*}{ BMI status } & Normal & 21 \\
\hline & Overweight & 32 \\
\hline & Obese & 47 \\
\hline \multirow[t]{2}{*}{ Smoking status } & Yes & 20.6 \\
\hline & No & 79.4 \\
\hline \multirow[t]{2}{*}{ Alcohol consumption } & Yes & 3.7 \\
\hline & No & 96.3 \\
\hline \multirow{2}{*}{$\begin{array}{l}\text { Family history of } \\
\text { hypertension }\end{array}$} & Yes & 69.9 \\
\hline & No & 30.1 \\
\hline \multirow[t]{3}{*}{ Blood pressure status } & NT & 33.5 \\
\hline & PHT & 38.2 \\
\hline & HРТ & 28.3 \\
\hline
\end{tabular}

Note. Data are expressed as mean (SD) for continuous variables and percentage for categorical variables; $\mathrm{SD}=$ standard deviation.
Table 2 Overall mean (SD) for SBP, DBP, and other biochemical profiles of the study subjects

\begin{tabular}{ll}
\hline Variables & Mean (SD) \\
\hline SBP, mm Hg & $126.72(16.01)$ \\
DBP, mm Hg & $84.45(11.34)$ \\
FBS, mmol/L & $5.03(0.97)$ \\
TC, mmol/L & $5.78(1.04)$ \\
TG, mmol/L & $1.46(0.8)$ \\
HDL-C, mmol/L & $1.33(0.32)$ \\
LDL-C, mmol/L & $3.77(0.94)$ \\
Hs-CRP, mg/L & $2.79(2.65)$ \\
\hline
\end{tabular}

Note. $\mathrm{SD}=$ standard deviation; $\mathrm{SBP}=$ systolic blood pressure; $\mathrm{DBP}=$ diastolic blood pressure; $\mathrm{FBS}=$ fasting blood sugar; $\mathrm{TC}$ $=$ total cholesterol; $\mathrm{TG}=$ triglycerides; HDL-C $=$ high density lipoprotein cholesterol; LDL-C = low density lipoprotein cholesterol; hs-CRP = high sensitivity C-Reactive Protein

$(91.9 \%)$. More than half of the subjects were nonsmokers and non-alcohol consumers. When categorised according to the BMI status, almost half of the subjects recruited in this study were obese. The range of SBP in subjects with normal BMI status was from $93 \mathrm{~mm} \mathrm{Hg}$ to $157 \mathrm{~mm} \mathrm{Hg}$. While for overweight subjects, the

Table 3 Association between cardiovascular risk factors with blood pressure groups in the unadjusted model

\begin{tabular}{|c|c|c|c|c|c|c|}
\hline \multirow{3}{*}{ Variables } & \multicolumn{6}{|c|}{ Prehypertensive $(n=109)$} \\
\hline & \multirow[t]{2}{*}{ B } & \multirow[t]{2}{*}{ SE } & \multirow[t]{2}{*}{$\mathrm{P}$} & \multirow[t]{2}{*}{ OR } & \multicolumn{2}{|c|}{$95 \% \mathrm{CI}$} \\
\hline & & & & & Lower & Upper \\
\hline Age & 0.025 & 0.021 & 0.234 & 1.026 & 0.984 & 1.069 \\
\hline Male $^{a}$ & 1.028 & 0.316 & $0.001 *$ & 2.796 & 1.505 & 5.194 \\
\hline Smoking $b$ & 0.588 & 0.400 & 0.142 & 1.8 & 0.821 & 3.945 \\
\hline $\begin{array}{l}\text { Alcohol } \\
\text { consumptionc }\end{array}$ & 0.399 & 1.234 & 0.747 & 1.49 & 0.133 & 16.738 \\
\hline $\begin{array}{l}\text { Parent's } \\
\text { history of } \\
\text { HPTd }^{\text {d }}\end{array}$ & 0.663 & 0.318 & $0.037^{*}$ & 1.94 & 1.041 & 3.614 \\
\hline \multicolumn{7}{|l|}{ BMI statuse } \\
\hline Obese & 1.656 & 0.399 & $<0.001 *$ & 5.238 & 2.394 & 11.46 \\
\hline $\begin{array}{l}\text { Over } \\
\text { weight }\end{array}$ & 0.386 & 0.386 & 0.317 & 1.471 & 0.69 & 3.136 \\
\hline FBS & 0.655 & 0.277 & $0.018^{*}$ & 1.924 & 1.118 & 3.314 \\
\hline $\begin{array}{l}\text { Total } \\
\text { cholesterol }\end{array}$ & 0.061 & 0.148 & 0.678 & 1.063 & 0.796 & 1.421 \\
\hline TG & 1.376 & 0.281 & $<0.001 *$ & 3.957 & 2.28 & 6.866 \\
\hline HDL-C & -2.24 & 0.521 & $<0.001 *$ & 0.107 & 0.038 & 0.297 \\
\hline LDL-C & 0.102 & 0.162 & 0.531 & 1.107 & 0.805 & 1.522 \\
\hline Hs-CRP & 0.163 & 0.066 & $0.014^{*}$ & 1.177 & 1.034 & 1.341 \\
\hline
\end{tabular}




\begin{tabular}{|c|c|c|c|c|c|c|}
\hline \multicolumn{7}{|c|}{ Hypertensive $(n=86)$} \\
\hline Variables & $\mathrm{B}$ & SE & $\mathrm{P}$ & OR & \multicolumn{2}{|l|}{$95 \% \mathrm{CI}$} \\
\hline & & & & & Lower & Upper \\
\hline Age & 0.087 & 0.023 & $<0.001 *$ & 1.091 & 1.042 & 1.143 \\
\hline Male $^{a}$ & 1.049 & 0.327 & $0.001 *$ & 2.854 & 1.502 & 5.422 \\
\hline Smoking ${ }^{\mathrm{b}}$ & 0.588 & 0.41 & 0.152 & 1.8 & 0.806 & 4.019 \\
\hline $\begin{array}{l}\text { Alcohol } \\
\text { consumption }\end{array}$ & 1.846 & 1.081 & 0.088 & 6.333 & 0.762 & 52.66 \\
\hline $\begin{array}{l}\text { Parent's } \\
\text { history of } \\
\text { HPT }^{d}\end{array}$ & 0.979 & 0.342 & $0.004^{*}$ & 2.663 & 1.361 & 5.207 \\
\hline \multicolumn{7}{|l|}{ BMI statuse } \\
\hline Obese & 3.296 & 0.602 & $<0.001 *$ & 27 & 8.299 & 87.84 \\
\hline Overweight & 2.209 & 0.588 & $<0.001 *$ & 9.103 & 2.874 & 28.83 \\
\hline FBS & 0.667 & 0.279 & $0.017^{*}$ & 1.948 & 1.127 & 3.367 \\
\hline Total & 0.283 & 0.152 & 0.062 & 1.327 & 0.986 & 1.786 \\
\hline TG & 1.043 & 0.275 & $<0.001 *$ & 2.839 & 1.655 & 4.87 \\
\hline HDL-C & -2.412 & 0.549 & $<0.001 *$ & 0.09 & 0.031 & 0.263 \\
\hline LDL-C & 0.259 & 0.169 & 0.124 & 1.296 & 0.931 & 1.804 \\
\hline Hs-CRP & 0.246 & 0.067 & $<0.001 *$ & 1.279 & 1.122 & 1.459 \\
\hline
\end{tabular}

Note. Multinomial Logistic Regression; Normotensive was set as the reference group; $\mathrm{B}=$ estimated coefficient; $\mathrm{SE}=$ standard error; $\mathrm{P}$ $=\mathrm{P}$-value; $\mathrm{OR}=$ odds ratio; $\mathrm{CI}=$ confidence interval; ${ }^{\mathrm{a} C o m p a r e d}$ to female, ${ }^{b}$ compared to non-smoker, ${ }^{\mathrm{c}}$ compared to non-alcohol consumer, dcompared to subjects without a parental history of hypertension, ${ }^{\mathrm{e}}$ compared to Normal BMI status; *statistically significant at $\mathrm{P}<0.05,95 \%$ confidence interval.

minimum SBP was $94 \mathrm{~mm} \mathrm{Hg}$, and the maximum SBP was $176 \mathrm{~mm} \mathrm{Hg}$. The obese subjects had a range of SBP from $95 \mathrm{~mm} \mathrm{Hg}$ to $174 \mathrm{~mm} \mathrm{Hg}$. Meanwhile, the range of DBP in normal, overweight, and obese status were from $59 \mathrm{~mm} \mathrm{Hg}$ to $109 \mathrm{~mm} \mathrm{Hg}, 61 \mathrm{~mm} \mathrm{Hg}$ to $105 \mathrm{~mm} \mathrm{Hg}$, and $63 \mathrm{~mm} \mathrm{Hg}$ to $121 \mathrm{~mm} \mathrm{Hg}$ respectively. The baseline characteristics of the study subjects and the overall mean (SD) of SBP and DBP; and other biochemical profiles in the study population are presented in Tables 1 and 2 respectively.

In the crude model, it was found that all parameters except smoking, alcohol consumption, total cholesterol, and LDL-C were significantly associated with either prehypertensive or hypertensive groups. On the other hand, only parental history, FBS, triglyceride, HDL-C, and hs-CRP were significantly associated with blood pressure status in both groups.

It was also observed that age and overweight subjects were not significantly associated with prehypertension, but the association was significant in hypertensive subjects as shown in Table 3 .
Once the model was adjusted for all the significant covariates, the analysis showed that in the prehypertensive group, the association between gender and parents' history of hypertension were statistically significant ( $P=0.042$ and $P=0.040$ respectively). In men, the risk of developing prehypertension was greater than in females; concurrently, compared to subjects with nonhypertensive parents, it was even stronger in subjects with only one or both parents experiencing hypertension.

Age, gender, genetic factors, as well as BMI status (both overweight and obese) were significantly associated with blood pressure status in the hypertensive group. It revealed that with an age rise of one year in both groups, the risk of developing prehypertension and hypertension was $21 \%$ and $76 \%$ respectively $(\mathrm{OR}=1.021 ; 95 \% \mathrm{CI}, 0.972-1.073$ and $\mathrm{OR}=1.076 ; 1.018$ 1.136). In comparison, the risk of both prehypertension and hypertension in males is double as high as in females $(\mathrm{OR}=2.22 ; 1.029-4.808$ and $\mathrm{OR}=2.46 ; 1.047-5.789$, respectively). Overweight subjects are more likely to acquire prehypertension, however, relative to subjects with normal BMI status, obese subjects are expected to have a greater chance of developing hypertension $(\mathrm{OR}=$ $4.57,1.33-15.78 ; \mathrm{OR}=9.46,2.47-36.29)$.

Nonetheless, after adjustment of significant variables it appeared that hs-CRP was not significantly associated with both groups thus, could not be confirmed as the risk factor for hypertension by the above results. The results are summarised in Table 4.

\section{DISCUSSION}

Hypertension is one of the major risk factors for CVD, which is responsible for at least 45 and 51 percent of total deaths due to heart disease and stroke, respectively (World Health Organization, 2013). Across the globe, the prevalence of hypertension was highest in the African Region (46\%), followed by the South-East Asia Region (36\%), and lowest in the Region of America at $35 \% .{ }^{17}$ There was also a substantial difference between ethnic groups where non-Hispanic black adults reported the highest prevalence of hypertension, while nonHispanic Asian adults showed the lowest prevalence among all groups studied ${ }^{2}$. 
Table 4 Association between cardiovascular risk factors with blood pressure status in blood pressure groups in the adjusted model

\begin{tabular}{|c|c|c|c|c|c|c|c|c|c|c|c|c|}
\hline \multirow{3}{*}{$\begin{array}{l}\text { Cardiovascular } \\
\text { risk factors }\end{array}$} & \multicolumn{6}{|c|}{ PREHYPERTENSIVE } & \multicolumn{6}{|c|}{ HYPERTENSIVE } \\
\hline & \multirow[t]{2}{*}{ B } & \multirow[t]{2}{*}{ SE } & \multirow[t]{2}{*}{$\mathrm{P}$} & \multirow[t]{2}{*}{ OR } & \multicolumn{2}{|c|}{$\begin{array}{l}95 \% \text { Confidence } \\
\text { Interval for OR }\end{array}$} & \multirow[t]{2}{*}{ B } & \multirow[t]{2}{*}{ SE } & \multirow[t]{2}{*}{$\mathrm{P}$} & \multirow[t]{2}{*}{ OR } & \multicolumn{2}{|c|}{$\begin{array}{l}95 \% \text { Confidence } \\
\text { Interval for OR }\end{array}$} \\
\hline & & & & & Lower & Upper & & & & & Lower & Upper \\
\hline Age & 0.021 & 0.025 & 0.404 & 1.021 & 0.972 & 1.073 & 0.073 & 0.028 & $0.009 *$ & 1.076 & 1.018 & 1.136 \\
\hline Malea $^{a}$ & 0.799 & 0.393 & $0.042 *$ & 2.224 & 1.029 & 4.808 & 0.901 & 0.436 & $0.039 *$ & 2.46 & 1.047 & 5.789 \\
\hline $\begin{array}{l}\text { Parental } \\
\text { history } \\
\text { of } \\
\text { hypertension }\end{array}$ & 0.723 & 0.352 & $0.040^{*}$ & 2.062 & 1.034 & 4.112 & 0.986 & 0.395 & $0.013^{*}$ & 2.68 & 1.236 & 5.81 \\
\hline \multicolumn{13}{|l|}{ BMIc } \\
\hline Obese & 0.754 & 0.496 & 0.128 & 2.126 & 0.804 & 5.619 & 2.247 & 0.686 & $0.001 *$ & 9.46 & 2.467 & 36.288 \\
\hline Overweight & -0.183 & 0.438 & 0.677 & 0.833 & 0.353 & 1.967 & 1.52 & 0.632 & $0.016^{*}$ & 4.57 & 1.325 & 15.784 \\
\hline FBS & 0.365 & 0.282 & 0.195 & 1.441 & 0.829 & 2.502 & 0.253 & 0.288 & 0.378 & 1.29 & 0.733 & 2.264 \\
\hline TG & 0.266 & 0.295 & 0.367 & 1.305 & 0.732 & 2.328 & 0.529 & 0.301 & 0.079 & 1.7 & 0.941 & 3.06 \\
\hline HDL & -0.811 & 0.646 & 0.209 & 0.445 & 0.125 & 1.577 & -0.12 & 0.722 & 0.871 & 0.89 & 0.216 & 3.662 \\
\hline Hs-CRP & 0.087 & 0.08 & 0.273 & 1.091 & 0.933 & 1.276 & 0.134 & 0.084 & 0.108 & 1.14 & 0.971 & 1.348 \\
\hline
\end{tabular}

Note. Multinomial Logistic Regression; Normotensive was set as reference group; B= estimated coefficient; SE=standard error; $\mathrm{P}=\mathrm{P}$-value; $\mathrm{OR}=$ odds ratio; $\mathrm{CI}=$ confidence interval; ${ }^{\mathrm{a} C o m p a r e d}$ to female, ${ }^{\mathrm{b}}$ compared to Subjects without parent's history of hypertension, ${ }^{c}$ compared with Normal BMI; *statistically significant at $\mathrm{P}<0.05,95 \%$ confidence interval

In several multi-ethnic studies performed in a few regions of the world, it has also been documented that CRP levels vary by ethnicity. The link between hypertension and CRP, as well as the development and validity of cardiovascular risk assessment methods, was shown in various studies. Nonetheless, most studies have been carried out in Western populations in which most participants are Caucasians over 40 years of age. Therefore, data generalization may be applicable to such populations only. ${ }^{18,19}$ Aggregated data from Asian countries are also lacking and thus applying similar tools using hs-CRP levels from Western countries to Asian individuals might not be justified or accurate.

In view of its assay characteristics as a robust biomarker, hs-CRP becomes a preferred clinical biomarker of CVD globally. Some of the ideal features of hs-CRP are its stability, sensitivity, reproducibility, and ease of measurement with very marginal fluctuations. In either fresh, stored, or frozen plasma or serum, the uniform high sensitivity immunoassay is capable of detecting circulating CRP levels with comparable outcomes. In addition, the hs-CRP demonstrates a relatively limited degree of intra-individual heterogeneity between sexes, age, and ethnicity, as well as diurnal variation ${ }^{20}$. Hs-CRP has been widely used as a predictive tool for the future development of cardiovascular events as recommended by the CDC-AHA in 2003.

In this study, despite a positive association between hs-CRP and blood pressure in crude models, the correlation did not persist after adjusting for relevant confounders. This finding was in line with a few crosssectional studies by Pan and peers (2019) in Liangshan Yi Autonomous Prefecture of Sichuan Province, the Republic of China, and Fernandez-Real et. al (2001) and Bautista, Vera, Arenas, \& Gamarra (2005). Several epidemiological studies also showed the unsustainability of the hs-CRP and BP relationship. A prospective cohort study conducted in Japan showed that there was no correlation between the high hs-CRP alone and the increased development of hypertension in both men and women ${ }^{24}$. CARDIA has shown that there has been no substantial association between hs-CRP and perimenopausal hypertension ${ }^{25}$. On the other hand, a large cohort study by Sesso and co-workers (2003) that hs-CRP was positively associated with hypertension which indicated that the levels of hs-CRP played crucial roles in the further development of hypertension.

The association between hs-CRP and BP status was possibly caused by the multiple confounders namely 
age $^{26}$, gender ${ }^{27,28}$, genetic factors, and BMI status. ${ }^{29,30}$ The positive association between age and hypertension was also shown in Framingham Heart Study and other studies ${ }^{31,32}$. The possible mechanisms to explain these associations remain elusive. Changes in vascular stiffness might be the factors leading to arteriosclerotic structural modifications as well as calcification which results in an increment of blood pressure ${ }^{31}$. Males tend to have lower CRP values than females in. $27,28,33,34$ The risks of hypertension and cardiovascular diseases are generally higher in men than women. ${ }^{35}$ The mechanisms which cause gender dissimilarities in blood pressure regulation are unclear. However, androgens such as testosterone might play a significant role. ${ }^{36,37}$

It is well recognized that hypertension clusters in families ${ }^{38}$. Parikh and colleagues (2008) reported that the risk of hypertension in non-hypertensive offspring in the future highly increases with a positive family history. Thus, the presence of positive parental histories in subjects contributed to the positive association of CRP40. Tsai \& Tsai (2008) also reported that higher $\mathrm{BMI}$ are associated with higher CRP values. Increased fatty tissues in obese individuals raise the vascular resistance which subsequently increases the workload on the heart. Apart from changes in renal structure and function, the activation of the sympathetic nervous system is another important mechanism that is responsible for the pathogenesis of hypertension among obese individuals. ${ }^{41}$

CRP was shown to be associated with several cardiovascular risk factors in the present study. Several possible mechanisms which may explain the role of CRP in the development of hypertension leading to cardiovascular diseases, mainly, renin-angiotensinaldosterone system (RAAS), sympathetic nervous system, and inflammation. In smooth muscle cells, CRP was reported to independently up-regulate angiotensin II type 1 receptor which leads to elevation of blood pressure. ${ }^{42}$ In an acute stress response, proinflammatory cytokines were induced as a result of the activation of the sympathetic nervous system on cardiac myocytes causing over-activation of the $\beta$-adrenergic signalling system resulting in harmful cardiotoxic effects which are triggered by the inflammatory cascade ${ }^{43}$. However, the actual mechanisms are still unclear. Thus, further experimental studies are required to determine the causative effects of CRP on each cardiovascular risk factor.

There are a few limitations to this study. Firstly, it is a cross-sectional study involving a small sample size, thus, a temporal relationship between raised CRP and the development of hypertension cannot be deduced. Next, CRP role in the development of young adult hypertension is still unclear. A bigger population-based cohort study should be conducted to justify and validate the association in the population as well as to determine the causative effects of CRP on different cardiovascular risk factors.

\section{CONCLUSION}

Cumulatively, these data suggest that the observed association between circulating hs-CRP and blood pressure status is likely to be driven by all the abovementioned factors. Nonetheless, the hypothesis that hsCRP has an independent association with blood pressure status was not demonstrated in the present study. Early detection of hypertension status especially in young adults provides a better prognosis and prevention of progression towards CVD events. HsCRP predictive values for CVD among the Malaysian population may differ from other western and Asian countries. The findings of this study may suggest the need to develop our own rubric on cardiovascular risk assessment based on blood pressure and hs-CRP, especially for young adults.

\section{CONFLICT OF INTEREST}

There are no conflicts of interest.

\section{ACKNOWLEDGEMENT}

We would like to acknowledge the Ministry of Education of Malaysia, through the Fundamental Research Grant Scheme (FRGS16-056-0555) that has been the source of funding for this research. We would also like to thank the International Islamic University Malaysia (IIUM) research initiative grant scheme (RIGS 15-076-0076 and RIGS 15-077-0077) for the extra financial support. 


\section{REFERENCES}

1. Feigin VL, Roth GA, Naghavi M, Parmar P, Krishnamurthi R, Chugh S, et al. Global burden of stroke and risk factors in 188 countries, during 1990-2013: A systematic analysis for the Global Burden of Disease Study 2013. Lancet Neurol. 2016;15(9):913-24.

2. Yoon SS u. S, Carroll MD, Fryar CD. Hypertension Prevalence and Control Among Adults: United States, 2011-2014. NCHS Data Brief. 2015;(220):1-8.

3. Chia YC, Ching SM. Hypertension and the development of New onset chronic kidney disease over a 10 year period: A retrospective cohort study in a primary care setting in Malaysia. BMC Nephrol. 2012;13(1):173.

4. Selassie A, Wagner CS, Laken ML, Ferguson ML, Ferdinand KC, Egan BM. Progression is accelerated from prehypertension to hypertension in blacks. Hypertension. 2011;58(4):579-87.

5. O'Donnell CJ, Elosua R. Cardiovascular Risk Factors. Insights From Framingham Heart Study. Rev Española Cardiol. 2008;61(3):299-310.

6. Paciaroni M, Bogousslavsky J. Primary and secondary prevention of Ischemic Stroke. Vol. 63, European Neurology. 2010. p. 267-78.

7. WHO. WHO - Cardiovascular diseases (CVDs). Cardiovascular diseases (CVDs). 2015.

8. Bassuk SS, Rifai N, Ridker PM. High-sensitivity Creactive protein: Clinical importance. Curr Probl Cardiol. 2004;29(8):439-93.

9. Wu AHB, Tsongalis GJ. Correlation of polymorphisms to coagulation and biochemical risk factors for cardiovascular diseases. Am J Cardiol. 2001;87(12):1361-6.

10. Mestas J, Ley K. Monocyte-Endothelial Cell Interactions in the Development of Atherosclerosis. Vol. 18, Trends in Cardiovascular Medicine. 2008. p. 228-32.

11. Rader DJ, Daugherty A. Translating molecular discoveries into new therapies for atherosclerosis. Nature. 2008;451(7181):904-13.

12. Libby P, Okamoto Y, Rocha VZ, Folco E. Inflammation in atherosclerosis: transition from theory to practice. Circ J. 2010;74(February):21320.
13. Willerson JT, Ridker PM. Inflammation as a Cardiovascular Risk Factor. Circulation. 2004;109 (21 suppl 1):1360-9.

14. Napoli C, de Nigris F, Williams-Ignarro S, Pignalosa O, Sica V, Ignarro LJ. Nitric oxide and atherosclerosis: An update. Vol. 15, Nitric Oxide Biology and Chemistry. 2006. p. 265-79.

15. Boncler M, Rywaniak J, Szymański J, Potempa L a, Rychlik B, Watała C. Modified C-reactive protein interacts with platelet glycoprotein Ib $\alpha$. Pharmacol Rep. 2011;63(2):464-75.

16. Sesso HD, Buring JE, Rifai N, Blake GJ, Gaziano JM, Ridker PM. C-reactive protein and the risk of developing hypertension. JAMA - J Am Med Assoc. 2003;290(22):2945-51.

17. World Health Organization. A global brief on Hypertension - World Health Day 2013. World Health Organization. 2013.

18. Blake GJ, Rifai N, Buring JE, Ridker PM. Blood Pressure, C-Reactive Protein, and Risk of Future Cardiovascular Events. Circulation. 2003;108 (24):2993-9.

19. Bautista LE, Atwood JE, O'Malley PG, Taylor AJ. Association between C-reactive protein and hypertension in healthy middle-aged men and women. Coron Artery Dis. 2004;15(6):331-6.

20. Calabrò P, Golia E, Yeh ETH. Role of C-reactive protein in acute myocardial infarction and stroke: Possible therapeutic approaches. Curr Pharm Biotechnol. 2012;13(1):4-16.

21. Pan L, Li G, Wan S, Yihuo WL, Yang F, Li Z, et al. The association between high-sensitivity $\mathrm{C}$ reactive protein and blood pressure in Yi people. BMC Public Health. 2019;19(1):991.

22. Fernandez-Real JM, Vayreda M, Richart C, Gutierrez C, Broch M, Vendrell J, et al. Circulating interleukin 6 levels, blood pressure, and insulin sensitivity in apparently healthy men and women. J Clin Endocrinol Metab. 2001;86 (3):1154-9.

23. Bautista LE, Vera LM, Arenas I a, Gamarra G. Independent association between inflammatory markers (C-reactive protein, interleukin-6, and TNF-alpha) and essential hypertension. J Hum Hypertens. 2005;19(2):149-54.

24. Fujii M, Ohnishi H, Saitoh S, Akasaka H, Miura T, Mori M. The combination of abdominal 
obesity and high-sensitivity C-reactive protein predicts new-onset hypertension in the general Japanese population: The Tanno-Sobetsu study. Hypertens Res. 2015;38(6):426-32.

25. Ebong IA, Schreiner P, Lewis CE, Appiah D, Ghelani A, Wellons M. The association between high-sensitivity $\mathrm{C}$-reactive protein and hypertension in women of the CARDIA study. Menopause. 2016;23(6):662-8.

26. Tsai H-J, Tsai AC-H. The association of plasma C-reactive protein levels with anthropometric and lipid parameters in elderly Taiwanese. Asia Pac J Clin Nutr. 2008;17(4):651-6.

27. Woloshin S, Schwartz LM. Distribution of Creactive protein values in the United States. N Engl J Med. 2005;352(15):1611-3.

28. Ahmadi-Abhari S, Luben RN, Wareham NJ, Khaw K-T. Distribution and determinants of Creactive protein in the older adult population: European Prospective Investigation into CancerNorfolk study. Eur J Clin Invest. 2013;43(9):899_ 911.

c8\&s $=868 \mathrm{dc} 6 \mathrm{~d} 450 \mathrm{af0} 08 \mathrm{c} 3476 \mathrm{~b} 02 \mathrm{bc50fb} 4681 \mathrm{f} 40$ 00de

29. Timpson NJ, Nordestgaard BG, Harbord RM, Zacho J, Frayling TM, Tybjærg-Hansen A, et al. C-reactive protein levels and body mass index: Elucidating direction of causation through reciprocal Mendelian randomization. Int J Obes. 2011;35(2):300-8.

30. Park HS, Park JY, Yu R. Relationship of obesity and visceral adiposity with serum concentrations of CRP, TNF- $\alpha$ and IL-6. Diabetes Res Clin Pract. 2005;69(1):29-35.

31. Pinto E. Blood pressure and ageing. Vol. 83, Postgraduate Medical Journal. 2007. p. 109-14.

32. Mungreiphy NK, Kapoor S, Sinha R. Association between BMI, Blood Pressure, and Age: Study among Tangkhul Naga Tribal Males of Northeast India. J Anthropol. 2011;2011:1-6.

33. Zhao Y, Wang R, Ma X, Yan X, Zhang Z, He X, et al. Distribution of $\mathrm{C}$-reactive protein and its association with cardiovascular risk factors in a population-based sample of Chinese. Dis Markers. 2010;28(6):333-42.

34. Saito I, Sato S, Nakamura M, Kokubo Y, Mannami T, Adachi H, et al. A low level of C- reactive protein in Japanese adults and its association with cardiovascular risk factors: The Japan NCVC-Collaborative Inflammation Cohort (JNIC) Study. Atherosclerosis. 2007;194(1):23844.

35. Nwankwo T, Yoon S, Burt V, Gu Q. Hypertension among adults in the United States: National Health and Nutrition Examination Survey, 2011-2012. NCHS Data Brief. 2013; (133):1-8.

36. Gillis EE, Sullivan JC. Sex Differences in Hypertension: Recent Advances. Hypertension. 2016;68(6):1322-7.

37. Harshfield GA, Alpert BS, Pulliam DA, Somes GW, Wilson DK. Ambulatory Blood Pressure Recordings in Children and Adolescents. Pediatrics. 1994;94(2).

38. Stamler R, Stamler J, Riedlinger WF, Algera G, Roberts RH. Family (parental) history and prevalence of hypertension. Results of a nationwide screening program. JAMA. 1979;241 (1):43-6.

39. Parikh NI, Pencina MJ, Wang TJ, Benjamin EJ, Lanier KJ, Levy D, et al. A risk score for predicting near-term incidence of hypertension: the Framingham Heart Study. Ann Intern Med. 2008;148(2):102-10.

40. Jose Diaz J, Arguelles J, Malaga I, Perillan C, Dieguez A, Vijande M, et al. C-reactive protein is elevated in the offspring of parents with essential hypertension. Arch Dis Child. 2007;92(4):304-8.

41. Grassi G, Seravalle G, Cattaneo BM, Bolla GB, Lanfranchi A, Colombo M, et al. Sympathetic activation in obese normotensive subjects. Hypertension. 1995;25(4 Pt 1):560-3.

42. Wang CH, Li SH, Weisel RD, Fedak PW, Dumont AS, Szmitko P, et al. C-reactive protein upregulates angiotensin type 1 receptors in vascular smooth muscle. Circulation. 2003;107 (13):1783-90.

43. El-Armouche A, Eschenhagen T. $\beta$-Adrenergic stimulation and myocardial function in the failing heart. Vol. 14, Heart Failure Reviews. 2009. p. 225 -41 . 